\title{
The nurse entrepreneur: empowerment needs, challenges, and self-care practices
}

Marla J Vannucci'

Sharon M Weinstein ${ }^{2}$

'Psychology Department, Adler University, Chicago, IL, ${ }^{2}$ SMW Group,

North Bethesda, MD, USA

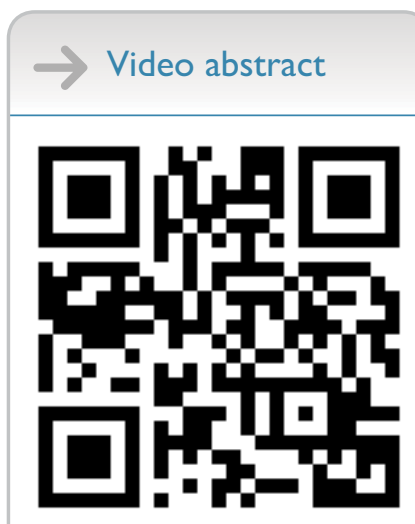

Point your SmartPhone at the code above. If you have a $Q R$ code reader the video abstract will appear. Or use: http://youtu.be/8Gt90fepr4s
Correspondence: Marla J Vannucci

Adler University, 17 N. Dearborn,

Chicago, IL 60630, USA

$\mathrm{Tel}+\mathrm{I} 3126624350$

Email mvannucci@adler.edu
This article was published in the following Dove Press journal:

Nursing: Research and Reviews

22 September 2017

Number of times this article has been viewed

Abstract: The purpose of this exploratory study was to better understand the experiences and challenges of nurse entrepreneurs. Nurse entrepreneurs $(\mathrm{N}=44)$ reported on their transitions from employment to entrepreneurship, key motivators in the decision to start a business, and the challenges they face as entrepreneurs in the health care field. Additionally, participants completed the 33-item Mindful Self-Care Scale - Short, which measured their self-care activities and behaviors in six domains: Physical Care, Supportive Relationships, Mindful Awareness, Self-compassion/Purpose, Mindful Relaxation, and Supportive Structure. Nurse entrepreneurs reported higher rates of self-care practices than a norm community sample, and age was positively correlated with higher rates of self-care practices. Nurse entrepreneurs reported that factors related to psychological empowerment, such as meaning/purpose, having an impact, need for growth, and getting to make decisions, were more critical motivators in the decision to start a business than factors associated with structural empowerment, such as financial gain and job or organizational constraints. Some work/life balance challenges, such as juggling multiple roles in a business, balancing one's own needs with those of others, time management, and addressing both family and business needs, were associated with fewer self-care behaviors. The biggest challenges to success that were identified, such as implementing a marketing strategy, networking, and accessing mentorship, were all related to relying on connections with others. The results of this study will benefit nurse entrepreneurs, potential nurse entrepreneurs, and others in the health care delivery system.

Keywords: career development, entrepreneurship, mindfullness, work/life balance, health care

\section{Introduction}

Nurse entrepreneurs fill the gaps in the current health care delivery system by supporting the development of targeted products and services, enhanced technology, software, and safety systems. A nurse entrepreneur has been defined as "a proprietor of a business that offers nursing services of a direct care, educational, research, administrative, or consultative nature". ${ }^{1}$ Nurse entrepreneurs may build their businesses to develop and distribute medical products or devices, offer direct patient care or patient advocacy, educate or train other professionals or community members, or provide health care-related consultation, among other functions. As more nurses move beyond the bedside to explore entrepreneurship, it is important to identify best practices and the skill sets that are transferable from direct caregiving to business leadership. It is also important to learn about how nurses have shifted perspective to make the transition, including the need for self-care. Despite the challenges that nurse entrepreneurs face, entrepreneurship can provide opportunities for nurses to have a more significant impact, 
achieve greater career and life satisfaction, and experience an enhanced sense of empowerment. ${ }^{2}$

The current state of health care in the USA and the climate of health care reform have led nurse entrepreneurs to focus on alternative models of care to provide patients and clients with a higher quality of life at more affordable prices and often with quicker access. Recent trends include steeply rising costs, changes in health care reimbursement, increased competition, an aging population, an increase in chronic illness, the advance and integration of technology, and increased population diversity. ${ }^{3}$ There has been a call to develop "creative, innovative, and entrepreneurial" approaches to fill the gaps in care to address these issues and others. ${ }^{4}$ Many of these trends have shifted our health care focus from an acute care model to one of prevention and detection.

Although there are many examples of nurse entrepreneurs even from the earliest days of the profession, including Florence Nightingale and Clara Barton, ${ }^{4}$ and although there are well-established historical and current models of nurses working independently as contractors or private registry, ${ }^{5}$ the structure of the health care system and academic and clinical training programs have in large part not supported the development of nurse leadership competencies. As per the Institute of Medicine's Initiative on the Future of Nursing, ${ }^{6}$ nurses are not generally provided with education or socialization related to administrative and leadership skills and roles in their academic programs. This Institute of Medicine report suggests that nurses must not only access education to develop competencies outside of their clinical expertise, such as attending business classes, but also shift their perspective on their professional roles. In the absence of formal education, training, or institutional support, nurse entrepreneurs typically have had to develop their own knowledge base and best practices. Additionally, although many nurses have turned to entrepreneurship as a vehicle to prevent burnout, ${ }^{7}$ financial demands often require nurse business owners to continue to hold part- or full-time organizational positions. At the same time, the unique challenges of the entrepreneurial context, such as having to fulfill multiple professional roles, may also present obstacles to maintaining self-care practices that would prevent burnout.

Currently, there is a dearth of literature that examines nurse entrepreneurship. The most recent prevalence assessment speculated that nurse-owned businesses represented a small percentage among all entrepreneurial businesses, and that nurse entrepreneurs made up only $0.5 \%-1 \%$ of all nurses. ${ }^{1}$ Since that accounting, health care reform, regulatory changes, technology, and rising care costs have led to significant growth in the number of nurse-owned businesses. While exact numbers have not been reported, a general sense exists that nurse entrepreneurship is greatly expanding. ${ }^{8,9}$ Primarily anecdotal or trade publications address nurse entrepreneurship as a trend within the health care industry, but little academic research addresses the experience of the nurse entrepreneur. ${ }^{2}$

\section{Nurse stress, burnout, and self-care}

Burnout has long been identified as an issue in the nursing field, ${ }^{10-13}$ and books on burnout, self-care, and work/life balance have specifically targeted the nurse population., ${ }^{74-16}$ Those drawn to nursing typically are devoted to caring for others, which can lead to development of compassion fatigue and the need to put their own needs on the back burner; in fact, those who work in professions geared toward caring for others are at higher risk for burnout. ${ }^{17}$ In institutional settings, nurse stress can be related to physical requirements of the job, witnessing of patient pain and suffering, long hours and other staffing issues, and interpersonal conflicts and issues. ${ }^{18}$ The work environment also plays a key role in burnout. A current trend toward healthier workplaces is aimed at promoting overall well-being, positive culture, and a sustainable workforce. Institutionally endorsed strategies for work/life balance help create supportive, healthy work environments, strengthen employee commitment and loyalty, and result in more productive workplaces and improved patient outcomes. ${ }^{19-21}$ Despite this recent trend, nurses continue to struggle in unsupportive work climates. Nurses are at the heart and soul of health care, and yet, they sometimes do not have time for self-care and renewal activities - activities that would make them whole and enhance their well-being. From an unrealistic workload, due to inadequate staffing and excessive paperwork, to fluctuating schedules associated with changing shifts, mandatory overtime, floating without appropriate orientation, moral and ethical dilemmas, and interpersonal conflict with physician colleagues, nurses experience significant demands, physically, emotionally, and interpersonally.

Historically, nursing has been a primarily female field, and the need to juggle work and family demands has been cited as a significant stressor for nurses. ${ }^{18}$ The growing number of men in nursing coincides with a trend toward men participating in household roles typically assigned to women. ${ }^{22}$ Thus, to some extent, male nurses also likely experience stress related to balancing family and household needs with the demands of working in a caregiving role. Both men and women need to develop meaningful, engaging, and rewarding relationships, while allowing time to care for themselves. 
Social support has been identified as a factor that may mitigate the impact of nurse stress on well-being and functioning. ${ }^{23,24}$ Social support may involve other professionals or personal connections, and may consist of seeking guidance or information, asking for specific assistance from others, emotional support, or encouragement. ${ }^{25}$ Additionally, empowerment has been linked with lower nurse stress and burnout, as well as greater well-being. ${ }^{26,27}$ Empowerment has been described as having two dimensions: structural empowerment and psychological empowerment. ${ }^{18}$ Structural empowerment refers to advancement opportunities, formal or informal power, resources, and access to information, within an organization or work environment. ${ }^{28}$ Psychological empowerment refers to meaning or purpose, self-determination, a sense of competence, and the capacity to have an impact, ${ }^{29,30}$ and can develop from one's experience of the self in relation to a profession, other professionals, or a specific organization. Both structural and psychological empowerment are believed to contribute to a sense of control and agency in the work experience, ${ }^{28,31}$ and some have postulated that psychological empowerment has a direct impact on well-being, but mediates the relationship between structural empowerment and well-being. ${ }^{27}$

Figley $^{32}$ has described the importance of self-care, especially for helping professionals who tend to the well-being of others. Self-care strategies, including relaxation, meditation, accessing social support, exercise, sensory experiences, such as listening to music, and cognitive strategies, such as active self-acceptance and positive self-talk, can prevent or decrease the symptoms of burnout. ${ }^{33-36}$

\section{Stress and self-employment}

Stress and burnout can also accompany self-employment, and these experiences may be related to factors such as balancing family and business demands, lack of social support, ${ }^{37}$ and financial uncertainty. ${ }^{38}$ Some research has suggested that control over one's work is a mediator in the stress/self-employment relationship. ${ }^{39}$ Although workplace stress cannot be eliminated completely, the negative stressors can be reduced when nurse entrepreneurs make caring for themselves a priority. Life is a balancing act, and nurses in all settings, especially entrepreneurial roles, can enhance well-being and productivity with effective self-care strategies. This study aimed to better understand the experiences of nurse entrepreneurs, their motives for entrepreneurship, the challenges they face, and the strategies they employ to cope with these challenges.

\section{Subjects and methods}

Following Adler University Institutional Review Board approval, data were collected in February 2017 using an online survey. A convenience sample of nurse entrepreneurs was identified through nursing professional organizations and word of mouth. The professional organizations serve nurses in the USA and Canada, but participants were not asked to identify the geographic location of their business; thus, no exclusions were implemented based upon location. An email describing the study and containing a link to the survey was shared with potential participants through professional listservs, newsletters, and membership email lists. Nurses of any academic level (eg, Diploma, AD/ADN, BA/ $\mathrm{BS} / \mathrm{BSN}, \mathrm{MA} / \mathrm{MS}, \mathrm{PhD} / \mathrm{EdD} / \mathrm{DNP}$ ) and with any relevant nurse credential or licensure (eg, RN, LPN) were included. Participants could hold a retired status practitioner license, and may or may not have been certified in a specialty practice approved by The Accreditation Board for Specialty Nursing Certification. Nurse practitioners who were not engaged in entrepreneurship outside of an employing agency or institution were excluded from the study. Participants who were employed part or full-time by an agency or institution were included, if they were engaged in entrepreneurship outside of an employment scenario.

\section{Measures}

Participants completed an original, online survey that requested information about their professional backgrounds, transition to entrepreneurship, and experiences as nurse entrepreneurs. The survey included Likert-type items, such as those that asked participants how critical certain factors were in their decision to enter entrepreneurship, as well as open-ended items. For open-ended survey items, responses were reviewed using Excel to identify emergent themes, and a count was conducted to determine the frequency with which themes and common answers occurred. Open-ended responses were assessed by two reviewers to ensure validity of the identified themes, as well as the assignment of responses to specific theme categories.

Additionally, they completed the 33-item Mindful SelfCare Scale - Short (MSCS). ${ }^{40}$ Cook-Cottone defines selfcare as "the daily process of being aware of and attending to one's basic physiological and emotional needs including the shaping of one's daily routine, relationships, and environment as needed to promote self-care". ${ }^{41}$ The MSCS is a highly reliable instrument ( 33 items; $\alpha=0.89$ ) that consists of six domains measuring different types of behavior aimed 
to influence one's physical and emotional well-being. The domains are: Physical Care (eg, exercise, nutrition, physical activity; eight items; $\alpha=0.84$ ), Supportive Relationships (eg, support system, having someone to listen; five items; $\alpha=0.86$ ), Mindful Awareness (eg, awareness of thoughts and feelings, mindfulness; four items; $\alpha=0.92$ ), Self-compassion/ Purpose (eg, accepting failure, finding meaning or purpose; six items; $\alpha=0.83$ ), Mindful Relaxation (eg, relaxation by intellectual, sensory, creative, or interpersonal means; six items; $\alpha=0.77$ ), and Supportive Structure (eg, organized and comfortable work environment; reasonable scheduling; four items; $\alpha=0.77)$. Respondents were asked to identify how often they participated in each activity within the past week, and to choose among "Never (0 days)", "Rarely (1 day)", "Sometimes (2-3 days)", "Often (3-5 days)", or "Regularly (6-7 days)". Norms for the MSCS (M=98.5, SD=19.5) were developed from a "community sample" $(n=778)$, although recruitment occurred primarily within an academic community, and the norm sample was predominantly White $(90 \%)$ and highly educated, with $51.6 \%$ having at least some graduate-level education. ${ }^{40}$ Cook-Cottone and Guyker calculated "average" (86-111), "low average" (59-85), and "high average" score ranges to assist with the interpretation of scores, as compared to the norm sample. They developed these ranges using a percentage of the SD, specifically twothirds of one $\mathrm{SD}$, or 12.8 points, from the mean to determine the low and high points of the average range, and 1.33 times the SD, or 25.9 points, from the low and high ends of the average range to determine the low end of the low average range and the high end of the high average range. ${ }^{40} \mathrm{~A}$ higher score on the MSCS indicates greater endorsement of self-care behaviors. When used as a tool for self-assessment, average MSCS domain scores may also be calculated to create a profile that compares one's activity among the six domains to identify areas for personal improvement. ${ }^{40}$

\section{Participants}

Forty-seven nurse entrepreneurs completed the online informed consent and initiated the survey; of these respondents, three initiated the survey, but did not complete any survey items. These 3 respondents were removed from the data analysis, leaving 44 participants included in the analysis. Participants ranged in age from 31 to 76 years, with a mean age of $55.16(\mathrm{SD}=11.61)$. Additional demographics are provided in Table 1. Using data from the The American Community Survey's most recent "Men in Nursing" report ${ }^{42}$ and "The US Nursing Workforce: Trends in Supply and Education", ${ }^{43}$ a two-sample Kolmogorov-Smirnov test yielded
Table I Participant demographics $(\mathrm{N}=44)$

\begin{tabular}{lll}
\hline Characteristic & $\mathbf{n}$ & $\%$ \\
\hline $\begin{array}{l}\text { Gender } \\
\text { Female }\end{array}$ & $4 \mathrm{I}$ & 93.2 \\
Male & 3 & 6.8 \\
Race/ethnicity & & \\
$\quad$ Asian or Asian-American, including Chinese, Japanese, & 2 & 4.5 \\
and others & & \\
Black or African-American & 6 & 13.6 \\
Hispanic or Latino, including Mexican, American, Central & I & 2.3 \\
American, and others & & \\
White, Caucasian, Anglo, European American; not Hispanic & 35 & 79.5 \\
Board certified & & \\
Yes & 28 & 63.6 \\
No & 16 & 36.4 \\
Employment & & \\
Work only in business & 25 & 56.8 \\
Part-time job plus business & 12 & 27.3 \\
Full-time job plus business & 6 & 13.6 \\
More than one job plus business & I & 2.3 \\
\hline
\end{tabular}

that the study population was representative of the general US nurse population in terms of gender $(\mathrm{D}=0.716)$ and race/ ethnicity $(\mathrm{D}=0.639)$. Participants were asked to report the target audience(s) for their business's products or services. Participants could identify one or more target audience(s) or setting(s), and reported the following: 19 (43.2\%) identified patient consumers, $15(34.1 \%)$ patient caregivers, $31(70.5 \%)$ health care providers of any type, 3 (6.8\%) community-based services, such as kiosks or services integrated into pharmacies or drugstores, $21(47.7 \%)$ health care facilities, and 15 $(34.1 \%)$ reported other target audience(s) or setting(s) that included "faculty", "lawyers", "health-related small business owners", "prisons or jails", "career-seekers" or "professional trainees", and "nursing home" or "senior living facility staff".

\section{Results}

Descriptive data were explored to provide a detailed picture of nurse entrepreneurs and their experiences. Additionally, correlational analyses and analysis of variance were utilized to explore the relationships among nurse entrepreneur backgrounds, demographics and experiences, and self-care practices. Finally, open-ended responses were analyzed to identify the themes to enrich understanding of the findings.

Participants were first asked "Tell us about your business". Consultation was the most often identified service, addressing a wide range of topics, including systems improvement, research consultation, professional development, marketing/ social media, device manufacturing, specialized service delivery, and expert witness or other legal consultation. Training and education was the next most frequently identified 
service, including delivery of educational programs, public speaking, coaching, tutoring, and writing or blogging. Patient advocacy services primarily focused on assisting patients and families to navigate the health care system, sometimes related to specific chronic illnesses or disorders. Several businesses focused on providing specialized direct services, including those targeting a specific illness, caregiver services, concierge nursing, and holistic health services. Last, a small number of participant businesses involved the sale of client care products, developed by participants to address specific patient care and recovery issues. Five participants (11.4\%) reported that their businesses, at least in part, focused specifically on work/life balance, holistic approaches to personal well-being, or other self-care practices for professionals and/ or patients/community members.

Participants reported a mean total MSCS score of 128.8 ( $\mathrm{SD}=16.64$; range=91-159). A one-sample $t$-test revealed that the study subjects' mean MSCS score was significantly higher than the norm sample $(t=11.99, p<0.001)$, suggesting that nurse entrepreneurs participate in self-care practices with greater frequency than the norm population. A modest but statistically significant positive correlation was found between total MSCS score and participant age $(r=0.311$, $p=0.045)$, as well as between age and the Self-compassion/ Purpose domain $(r=0.336, p=0.029)$. A series of analyses of variance were used to determine the relationship between employment status and self-care practices. Only Supportive Structure practices significantly differed among nurses with different employment statuses $(F(3,37)=4.837, p=0.006)$, suggesting that nurses who were employed in addition to running their businesses differed from nurses who only run businesses, in terms of the frequency with which they employ self-care practices, such as maintaining a manageable schedule, creating an organized and comfortable work environment, and intentionally balancing the needs of others with one's own goals.

To compare behavior across MSCS domains, average scores were calculated within each domain. Table 2 reports descriptive data for the MSCS domain averages. Participants mostly engaged in Supportive Relationships ( $\mathrm{M}=4.34$, $\mathrm{SD}=0.75)$, Mindful Awareness $(\mathrm{M}=4.26, \mathrm{SD}=0.77)$, and Self-compassion/Purpose ( $\mathrm{M}=4.19, \mathrm{SD}=0.67)$ behaviors. Physical Care was attended to the least $(\mathrm{M}=3.40, \mathrm{SD}=0.74)$.

Table 3 describes the "critical motivators" in participants' deciding to pursue entrepreneurship ("Please tell us how important the following factors were in your motivation to become a nurse entrepreneur [critical motivator, important
Table 2 Mindful Self-care Scale - Short: domain-averaged scores

\begin{tabular}{lllll}
\hline Domain & Mean & SD & Min. & Max. \\
\hline Supportive Relationships & 4.34 & 0.75 & 1.80 & 5.00 \\
Mindful Awareness & 4.26 & 0.77 & 2.25 & 5.00 \\
Self-compassion/Purpose & 4.19 & 0.67 & 2.50 & 5.00 \\
Mindful Relaxation & 3.89 & 0.71 & 2.00 & 5.00 \\
Supportive Structure & 3.83 & 0.91 & 1.00 & 5.00 \\
Physical Care & 3.40 & 0.74 & 1.75 & 4.75
\end{tabular}

Note: Higher score indicates greater level of self-care practice.

Abbreviations: Min, minumum; Max, maximum.

Table 3 Critical motivators to pursue entrepreneurship and factors critical to business success

\begin{tabular}{ll}
\hline Factor & Frequency, \% \\
\hline Motivators & \\
Personal meaning/fulfillment & 90.9 \\
Ability to make own decisions & 77.3 \\
Need for growth & 77.3 \\
Having an impact & 75.0 \\
Great idea for a product or service & 61.4 \\
Flexibility & 54.5 \\
Control over time & 50.0 \\
Better work/life balance & 47.7 \\
Lack of advancement & 31.8 \\
Being the boss & 29.5 \\
Can choose coworkers & 20.5 \\
Financial gain & 18.2 \\
Business success factors & \\
Marketing strategy & 61.4 \\
Network development & 47.7 \\
Mentorship & 47.7 \\
Finance and business skills & 43.2 \\
Sales & 43.2 \\
Clinical or specialty knowledge & 40.9 \\
Product or service development & 40.9 \\
Identification of a market niche & 34.1 \\
Social media strategy & 31.8 \\
Design or creative skills & 31.8 \\
Legal knowledge & 27.3 \\
Data management & 25.0 \\
Funding & 22.7 \\
\hline
\end{tabular}

Note: Frequencies indicate percentage of respondents listing factors as critical to their motivation or contributing to their business success.

or significant motivator, less important motivator, not an important motivator]"). The four most frequently identified motivators were personal meaning/fulfillment (90.9\%), the ability to make one's own decisions (77.1\%), the need for professional growth (77.1\%), and wanting to have a greater impact (75\%). Additional critical motivators identified by the participants were related to the desire to escape a negative work environment (eg, bullying), the need to adapt to personal physical or health challenges that prevented ongoing work in previous employment, and the desire to address limitations or challenges of the current health care delivery system. 
When asked about the factors most critical for their current business success ("Please tell us how important the following items are to increasing your success in your business right now [critical to my success, important to my success, less important to my success, not at all important to my success]"), the participants mostly identified having a marketing strategy (61.4\%), networking (47.7\%), and mentorship (47.7\%) as most critical (see Table 3).

In response to a question about the factors that may be potential barriers to achieving work/life balance (see Table 4; "How challenging are the following factors to your current experience of work/life balance? [always challenging,

Table 4 Primary challenges to work/life balance for nurse entrepreneurs

\begin{tabular}{ll}
\hline Factor & Always challenging, \% \\
\hline Juggling multiple business roles & 47.7 \\
Time management/scheduling & 38.6 \\
Balancing family vs business needs & 34.1 \\
Helping others vs helping myself & 34.1 \\
Maintaining physical well-being & 31.8 \\
Working in a job plus the business & 22.7 \\
Isolation & 22.7 \\
Financial burden & 20.5 \\
Having to make all decisions & 18.2 \\
Confidence in business abilities & 13.6 \\
\hline
\end{tabular}

sometimes challenging, less often challenging, never challenging]"), the participants reported juggling multiple roles in the business (47.7\%) and time management/scheduling $(38.6 \%)$ as the greatest challenges. In their open-ended responses, participants described struggling with "not overcommitting", "family tensions", "challenges with spousal support", "conflicting vision" of the future between the entrepreneur and family members, adapting to "external influences", such as legislation and regulatory changes, caring for young children while running the business, supervising staff, and travel. One participant wrote "travel is awful; you need to reframe everyday," and another wrote "traveling a lot makes getting exercise in a challenge." Having to learn quickly on the job without business knowledge was consistently described as a substantial challenge in participants' open-ended responses. One participant wrote "this business stuff has me in a quandary." Other responses included "business language is different from medical language," "business knowledge is limited," and "the learning curve has been very high...I had no idea what I was getting into."

A review of open-ended responses identified highly frequent comments related to themes consistent with elements of psychological and structural empowerment. Table 5 provides sample responses related to empowerment.

Table 5 Open-ended responses related to structural and psychological empowerment

\begin{tabular}{|c|c|}
\hline Theme & Example responses \\
\hline $\begin{array}{l}\text { Structural empowerment (resources, } \\
\text { advancement, information, power) }\end{array}$ & $\begin{array}{l}\text { "I got tired of waiting for someone to give me a job to practice... the way I knew it needed to be done" } \\
\text { "started blogging ... to cope with the bullying I received on the floor" } \\
\text { "[my] firm lacked depth to create recommendations ... believed I could create a company that could" } \\
\text { "they changed operating model and reduced salary" } \\
\text { "was told even with profit sharing I had maxed up on my income" } \\
\text { "my employer made five times what I made" } \\
\text { "not willing to pay me what I felt I was worth" } \\
\text { "was told I made enough money for a "nurse”" } \\
\text { "left clinical care ... and pursued further education" } \\
\text { "frustrations about the dysfunction and limits of our healthcare system" } \\
\text { "got laid off } 3 \text { times in } 5 \text { years" } \\
\text { "was told ... that I had too much experience for a ... position" }\end{array}$ \\
\hline $\begin{array}{l}\text { Psychological empowerment } \\
\text { (meaning, competence, self- } \\
\text { determination, impact) }\end{array}$ & $\begin{array}{l}\text { "my values were not in alignment with the organization I was working in" } \\
\text { "when I was not able to take a vacation when I wanted to, that was a pivotal point in my nursing career" } \\
\text { into areas that interest me" } \\
\text { "the ability to follow my personal inspiration" } \\
\text { "the number of people my work has touched" } \\
\text { "felt called to do something that was better" } \\
\text { "I am in charge of my future" } \\
\text { "providing opportunities to others" } \\
\text { "[success is] ... being viewed as an expert" } \\
\text { "feeding my nursing soul" } \\
\text { "personal satisfaction" } \\
\text { "recognition as an authority" } \\
\text { "make a difference within the healthcare industry" } \\
\text { "I am able to set my own schedule, complete work as I see fit, and take time off when I need to" }\end{array}$ \\
\hline
\end{tabular}


Table 6 reports correlations between work/life balance challenges experienced by the participants and self-care behavior, as measured by the domains of the MSCS. Although total MSCS scores were not significantly associated with work/life balance challenges, some domains were related to reported challenges. The Supportive Relationships domain was significantly negatively correlated with experiencing financial burden $(r=-0.37, p<0.05)$, difficulty with making all the decisions $(r=-0.39, p<0.05)$, lack of confidence in business abilities $(r=-0.33, p<0.05)$, and isolation $(r=-0.49$, $p<0.05)$. The Supportive Structure domain was significantly negatively correlated with the challenges of juggling multiple business roles $(r=-0.34, p<0.05)$, time management and scheduling $(r=-0.50, p<0.01)$, balancing business and family needs $(r=-0.47, p<0.01)$, balancing others' needs vs selfneeds $(r=-0.45, p<0.01)$, maintaining physical well-being $(r=-0.35, p<0.05)$, and managing financial burden $(r=-0.31$, $p<0.05)$. Behaviors in the Mindful Relaxation domain were negatively correlated with having to juggle multiple business roles $(r=-0.35, p<0.05)$.

\section{Discussion}

In this exploratory study, the primary goal was to better understand the experiences of nurse entrepreneurs, their motivations for a career transition, their challenges, and strategies to maintain work/life balance. Participants in this study reported a significantly higher frequency of self-care practices than a community population. Nurse entrepreneurs often start their own businesses to avoid the stressors they previously experienced in the employed work environment; their higher rates of self-care practices may reflect this goal to achieve greater self-care that initially led them to entrepreneurship. It is also possible that those who responded to the survey were not representative of all nurse entrepreneurs, but instead comprised a subsample having time to participate due to enhanced self-care activities or greater willingness to respond to an online survey. Nurse entrepreneurs who do not feel successful at work/life balance may have felt too overwhelmed to spare the time to complete the survey.

As might be expected, participants who worked full-time or more than full-time in addition to their businesses reported less self-care activity than those who worked exclusively in their businesses or held additional employment only on a parttime basis. As the sample was heavily skewed toward those with part-time only or no additional employment (84.1\%), the generally high rates of self-care practices overall in the sample may also be related to employment status that is not necessarily representative of all nurse entrepreneurs. Despite the sample demographics, maintaining full-time employment is a necessity for many as they grow their businesses. Several participants not only commented on the difficulty involved in balancing employment and entrepreneurship, but also on the importance of having a gradual shift for stability. Participants reported that they attempted to juggle both business and employment until they could no longer do so or left employment once they achieved a stable income. In fact, many who left employment abruptly did so either as the result of a negative experience in the workplace or due to a physical/health issue or personal life change that required leaving their employment. When asked about their business goals, several participants who were working full-time or more than full-time identified gaining the stability to work only in their business as a goal for the next 5 or 10 years.

Age was associated with higher rates of self-care activities overall, as well as within the Self-compassion/Purpose domain. The positive correlation between age and self-care may be explained by the fact that nurse entrepreneurs who are older are likely also more advanced in their careers and

Table 6 Correlations: mindful self-care practices and work/life balance challenges

\begin{tabular}{|c|c|c|c|c|c|c|c|}
\hline $\begin{array}{l}\text { Work/life balance } \\
\text { challenge }\end{array}$ & $\begin{array}{l}\text { MSCS } \\
\text { total }\end{array}$ & $\begin{array}{l}\text { Physical } \\
\text { Care }\end{array}$ & $\begin{array}{l}\text { Social } \\
\text { Support }\end{array}$ & $\begin{array}{l}\text { Mindful } \\
\text { Awareness }\end{array}$ & Structure & Relaxation & $\begin{array}{l}\text { Self- } \\
\text { compassion }\end{array}$ \\
\hline Others vs myself & -0.219 & -0.202 & -0.243 & -0.180 & $-0.448 * *$ & -0.188 & -0.199 \\
\hline Family vs business & -0.102 & -0.086 & 0.032 & -0.208 & $-0.466 * *$ & -0.119 & -0.147 \\
\hline Isolation & -0.138 & 0.224 & $-0.486 * *$ & -0.105 & -0.092 & -0.251 & -0.150 \\
\hline Working plus business & -0.022 & 0.201 & -0.107 & -0.070 & -0.269 & -0.077 & -0.131 \\
\hline Physical well-being & -0.156 & -0.039 & 0.181 & -0.054 & $-0.345^{*}$ & -0.215 & -0.196 \\
\hline Time management & -0.109 & -0.068 & -0.110 & 0.085 & $-0.498 * *$ & 0.017 & -0.188 \\
\hline Juggling multiple roles & -0.168 & 0.076 & -0.145 & -0.095 & $-0.340 *$ & $-0.348 *$ & -0.260 \\
\hline Decision making & -0.074 & 0.186 & $-0.390 *$ & -0.186 & -0.121 & -0.011 & -0.155 \\
\hline Confidence & 0.124 & 0.175 & $-0.332 *$ & 0.050 & $-0.14 \mid$ & 0.127 & 0.028 \\
\hline Financial burden & -0.170 & 0.051 & $-0.369 *$ & -0.170 & $-0.310 *$ & -0.186 & -0.251 \\
\hline
\end{tabular}

Note: $* p<0.05, * * p<0.01$.

Abbreviation: MSCS, Mindful Self-Care Scale. 
may now place a greater emphasis on quality of life than during earlier career stages. Demands for balancing the management of a household in addition to work may have decreased for older nurse entrepreneurs. If they have children, the children are probably older, even adults, requiring less care and time. Additionally, older nurse entrepreneurs have more work and life experience, and thus may be more skilled at integrating self-care practices into their daily lives. For nurse entrepreneurs who have run their businesses for longer periods of time, this may also be true. Entrepreneurs with a longer history in entrepreneurship may have learned over time how to integrate self-care, or alternately, may have businesses that are more stable or more developed, allowing increased time and space for self-care. The relationship between age and Self-compassion/Purpose practices suggests that later in their careers, nurse entrepreneurs may place a greater emphasis on personal meaning in their work over productivity, may be more accepting of failures and struggles, have a clearer sense of personal strengths and weaknesses, and may more frequently engage in selfencouragement vs self-criticism.

Research has supported the importance of empowerment in preventing burnout. ${ }^{44,45}$ Themes related to structural and psychological empowerment were consistently identified by reviewers in the open-ended responses. Respondents described their motivations for entrepreneurship either in terms of avoiding negative employment experiences, moving toward more positive and personally meaningful work experiences, or both. These categories of motivators are sometimes referred to as "push" or "necessity" motivators and "pull" or "opportunity" motivators. ${ }^{46,47}$ Economic trends, as well as personal experiences, can generate push motivators, or factors within employment experiences that push one toward entrepreneurship and out of traditional employment. Many participants cited market trends, health care systemic issues, and the economic environment as factors in the decision to open a business, in addition to personal events that put limits on traditional employment, such as illness or a change in family status. The desire for structural empowerment was evident in necessity motivators, such as the need to leave an abusive or constraining work environment, lack of advancement or opportunity, or limited access to resources needed to do the job effectively. Consistent with research that has suggested that women entrepreneurs are motivated more by opportunity than necessity, ${ }^{47}$ motivators identified as "most critical" by $75 \%$ or more of this predominantly female sample were related to psychological empowerment, specifically, personal meaning/fulfillment, the ability to make one's own decisions, the need for growth, and having an impact. The desire for increased control and autonomy was a prominent theme that emerged again and again, and this theme was represented both by necessity and opportunity motivators. Participants felt thwarted by institutional limitations and sought work that allowed for freedom from constraints, but even more importantly, they desired greater self-determination and ownership over their own futures.

The importance of social support was highlighted, including both professional and personal networks. Participants reported a higher frequency of self-care activity within the Supportive Relationships domain than any other. This domain includes practices such as spending time with others who are encouraging and supportive, accessing someone who would listen, such as a counselor or friend, populating one's life with people who will accept and respect "no", and scheduling time to be with special people. When asked what is most important for their business success right now, the top three items, marketing strategy, networking development, and mentorship, were all related to relationship building and engaging relationships for professional development. Many participants described the importance of professional organizations, such as those accessed for recruitment in the study, in their success thus far, and more specifically, opportunities provided by these organizations for communication and knowledge sharing, formal and informal mentorship, education and training, and simply feeling connected to others with similar goals and struggling with similar issues.

Nurse entrepreneurs use their nursing platform to educate, empower, and engage others. Their businesses identify existing challenges in health care delivery or education, develop workable solutions, and often bring new products to the market. From advanced practice registered nurses who provide direct care as licensed independent practitioners or within group practices to those who offer private case management, product development, or consulting services, the opportunities are abundant and growing, as economic, public health, and health care industry trends manifest. Their incentives for entrepreneurship may involve movement away from institutional constraints, but are more heavily driven by the need for psychological empowerment, through autonomy, impact, and personal meaning. They often promote self-care and in many cases, may have mastered the process themselves. In doing so, they take care of themselves to care better for others. Nurse entrepreneurs may have greater success in achieving work/ life balance or, alternately, the ability to blend their lifestyles to create and sustain a balancing act, potentially more so than other nurses. Future research should explore the self-care 
and work/life balance experiences of nurse entrepreneurs as they compare to nurses in other employment scenarios, in order to determine if this population is, in fact, unique from non-entrepreneurial nurses. Although this study's sample was representative of the field in terms of gender and race/ethnicity, access to a larger sample may expand understanding of how empowerment motivators and entrepreneurial challenges may differentially impact nurses with varying demographic characteristics and backgrounds, toward identifying the unique needs of nurse entrepreneur groups and resources to support them. For non-entrepreneurial nurses who are interested in entrepreneurship, understanding the barriers and obstacles to their making the transition may enhance their future capacity to enter entrepreneurship. Finally, participants in this study did not report on their actual levels of stress or well-being, and future efforts should investigate the effectiveness of self-care practices in the context of nurse entrepreneurs' experiences of stress and well-being. Nurse entrepreneurs are a fast-growing population, and overall, this study significantly enhanced understanding of their personal experiences, motivators, work/life balance challenges, and self-care practices.

\section{Acknowledgment}

The authors would like to thank Douglas Whiteside, $\mathrm{PhD}$, ABPP for his assistance with the manuscript.

\section{Disclosure}

Sharon M Weinstein is a member of the nursing professional organizations accessed for recruitment; however, neither author has received financial or personal benefit related to this study. The authors report no other conflicts of interest in this work.

\section{References}

1. International Council of Nurses. Guidelines on the nurse entre/intrapreneur providing nursing service. Geneva, Switzerland; 2004.

2. Shirey M. Advanced practice nursing. In: Fulton JS, Lyon BL, Goudreau KA, editors. Foundations of Clinical Nurse Specialist Practice. 2nd ed. New York, NY: Spring Publishing; 2014.

3. Guo KL. Core competencies of the entrepreneurial leader in health care organizations. Health Care Management. 2009;28(1):19-29.

4. Darbyshire P. An idea whose time has come: nursing entrepreneurialism. Whitireai Nurs Health J. 2014;21:9-14.

5. Whelan JC. When the business of nursing was the nursing business: the private duty registry system, 1900-1940. Online J Issues Nurs. 2012;17(2):6.

6. IOM (Institute of Medicine). The Future of Nursing: Leading Change, Advancing Health. Washington, DC: The National Academies Press; 2011.

7. Podlesni MD. Unconventional nurse: Going from burnout to bliss! Self published: 2013.
8. Carlson K. Nurse entrepreneurship is exploding across the US; 2015. Available from: http://exclusive.multibriefs.com/content/nurse-entrepreneurship-explodes-across-the-us/healthcare-administration. Accessed May 22, 2017.

9. Keyes L. Nurse entrepreneur trends; 2017. Available from: http://www. nurse-entrepreneur-network.com/public/727.cfm. Accessed May 22, 2017.

10. Garrosa E, Moreno-Jiménez B, Liang Y, González JL. The relationship between socio-demographic variables, job stressors, burnout, and hardy personality in nurses: an exploratory study. Int J Nurs Stud. 2008;45:418-442.

11. Gandoy-Crego M, Clemente M, Mayan-Santos JM, Espinosa P. Personal determinants of burnout in nursing staff at geriatric centers. Arch Gerontol Geriatr. 2009;48(2):246-249.

12. Hayes LJ, O'Brien-Pallas L, Duffield C, et al. Nurse turnover: a literature review. Int J Nurs Stud. 2006;43(2):237-263.

13. Menzies IEP. Nurses under stress. Int Nurs Rev. 1960;7:9-16.

14. McConnell EA. Burnout in the Nursing Profession: Coping Strategies, Causes, and Costs. St. Louis: Mosby; 1982.

15. Skinner J. Nursing by Heart: Transformational Self-care for Nurses. Winchester, UK: Ayni Books; 2015.

16. Weinstein S. B is for Balance: A Nurse's Guide for Enjoying Life at Work and at Home. Indianapolis, IN: Sigma Theta Tau International; 2009.

17. Maslach C. Job burnout: new directions in research and intervention. Curr Dir Psychol Sci. 2003;12:189-192.

18. Jennings BM. Work stress and burnout among nurses: role of the work environment and working conditions. In: Hughes RG. editor. Patient Safety and Quality: An Evidence-Based Handbook for Nurses. Rockville, MD: Agency for Healthcare Research and Quality; 2008.

19. American Association of Critical Care Nurses. AACN Standards for Establishing and Sustaining Healthy Work Environments: A Journey to Excellence. 2nd ed; 2016. Available from: https://www.aacn.org/wd/ hwe/docs/hwestandards2016.pdf. Accessed May 13, 2017.

20. American Association of Nurse Anesthetists. Promoting a culture of safety and healthy work environment; 2014. Available from: http:// www.aana.com/resources2/professionalpractice/Pages/Promoting-aCulture-of-Safety-and-Healthy-Work-Environment.aspx. Accessed May 13, 2017.

21. Seppalla E, Cameron K. Proof that positive work cultures are more productive. Harvard Business Review; 2015. Available from: https://hbr.org/2015/12/proof-that-positive-work-cultures-are-moreproductive. Accessed May 13, 2017.

22. Oláh LS, Richter R, Kowoska IE. The new roles of men and women and implications for families and societies. Families and Societies Working Paper Series, 11; 2014. Available from: http://www.familiesandsocieties.eu/wp-content/uploads/2014/12/WP11OlahEtA12014.pdf. Accessed May 13, 2017.

23. AbuAlRub RF. Job stress, job performance, and social support among hospital nurses. J Nurs Scholarsh. 2004;36(1):73-78.

24. Joiner T, Bartram T. How empowerment and social support affect Australian nurses' work stressors. Australian Health Rev. 2004;28(1):56-64.

25. Adams LY. Workplace Mental Health Manual for Nurse Managers. New York, NY: Springer; 2015.

26. Bartram T, Joiner TA, Stanton P. Factors affecting the job stress and job satisfaction of Australian nurses: implications for recruitment and retention. Contemporary Nurse. 2004;17(3):293-304.

27. Laschinger HK. A theoretical approach to studying work empowerment in nursing: a review of studies testing Kanter's theory of structural empowerment in organizations. Nurs Adm Q. 1996;20(2):25-41.

28. Kanter RM. Men and Women of the Corporation. 2nd ed. New York, NY: Basic Books; 1993.

29. Kluska KM, Laschinger-Spence HK, Kerr MS. Staff nurse empowerment and effort-reward imbalance. Can J Nurs Leadersh (Tor Ont). 2004;17(1):112-128.

30. Spreitzer GM. Psychological empowerment in the workplace: dimensions, measurement, and validation. Acad Manage J. 1995;38(5): $1442-1465$. 
31. Peterson NA, Zimmerman MA. Beyond the individual: toward a nomological network of organizational empowerment. Am J Community Psychol. 2004;34(1/2):129-145.

32. Figley CR. Compassion Fatigue: Coping with Secondary Traumatic Stress Disorder in those who Treat the Traumatized. New York, NY: Brunner-Routledge; 1995.

33. Alexander GK, Rollins K, Walker D, Wong L, Pennings J. Yoga for self-care and burnout prevention among nurses. Workplace Health Saf. 2015;63(10):462-470.

34. Mimura C, Griffiths P. The effectiveness of current approaches to workplace stress management in the nursing profession: an evidence-based literature review. Occup Environ Med. 2003;60(1):10-15.

35. Oman D, Hedberg J, Thoresen CE. Passage meditation reduces perceived stress in health professionals: a randomized, controlled trial. J Consult Clin Psychol. 2006;74(4):714-719.

36. Smith SA. Mindfulness-based stress reduction: an intervention to enhance effectiveness of nurses' coping with work-related stress. Int J Nurs Knowl. 2014;25(2):119-130.

37. Jamal M. Burnout and self-employment: a cross-cultural empirical study. Stress Health. 2007;23(4):249-256.

38. Klein KE. Dousing the flames of burnout. Bloomberg.com; 2006. Available from: https:/www.bloomberg.com/news/articles/2006-03-01/ dousing-the-flames-of-burnout. Accessed May 08, 2017.

39. Hessels J, Rietveld CA, van der Zwan P. Self-employment and workrelated stress: the mediating role of job control and job demand. J Bus Venturing. 2016;32(2):178-196.
40. Cook-Cottone CP, Guyker W. The development and validation of the Mindful Self-Care Scale: an assessment of practices that support positive embodiment. Mindfulness. 2017:1-15.

41. Cook-Cottone CP. Mindfulness and Yoga for Self-regulation: A Primer for Mental Health Professionals. New York, NY: Springer; 2015.

42. Landivar LC. Men in Nursing Occupations. Washington, DC: United States Census Bureau; 2013. Available from: https://www.census.gov/ people/io/files/Men_in_Nursing_Occupations.pdf. Accessed May 11, 2017.

43. Health Resources and Services Administration Bureau of Health Professions. The US Nursing Workforce: Trends in Supply and Education. National Center for Health Workforce Analysis; 2013. Available from: https://bhw.hrsa.gov/sites/default/files/bhw/nchwa/projections/ nursingworkforcetrendsoct2013.pdf. Accessed May 11, 2017.

44. Hochwälder J, Brucefors AB. Psychological empowerment at the workplace as a predictor of ill health. Pers Individ Differences. 2005;39(7): 1237-1248.

45. Spence Laschinger HK, Leiter M, Day A, Gilin D. Workplace empowerment, incivility, and burnout: Impact on staff nurse recruitment and retention outcomes. J Nurs Manag. 2009;17(3):302-311.

46. Dawson C, Henley A. "Push" vs "pull" entrepreneurship: an ambiguous distinction? Int J Entrepreneurial Behav Res. 2012;18(6):697-719.

47. Hughes KD. Pushed or pulled? Women's entry into self-employment and small business ownership. Gender Work Organ. 2003;10(4): $433-454$.
Nursing: Research and Reviews

\section{Publish your work in this journal}

Nursing: Research and Reviews is an international, peer-reviewed, open access journal publishing original research, reports, reviews and commentaries on all aspects of nursing and patient care. These include patient education and counseling, ethics, management and organizational issues, diagnostics and prescribing, health outcomes, economics and
Dovepress

resource management, improving patient safety in all settings. The manuscript management system is completely online and includes a very quick and fair peer-review system. Visit http://www.dovepress. com/testimonials.php to read real quotes from published authors. 